\title{
"YOUTUBESCOPIOS": \\ UNA EXPERIENCIA DE INNOVACIÓN Y CREATIVIDAD PARA CULTURA AUDIOVISUAL MEDIANTE EL RECURSO AL APRENDIZAJE POR PROYECTOS
}

\author{
Angélica García-Manso \\ Universidad de Extremadura
}

\begin{abstract}
RESUMEN: El presente artículo describe y analiza la propuesta bautizada como "Youtubescopios", un proyecto de innovación y creatividad para complementar los contenidos audiovisuales de las materias de ESO y Bachillerato. Consiste básicamente en la aplicación de las tecnologías añadidas a los smartphones para aprender y recrear las características del Séptimo Arte en sus orígenes. También pretende potenciar diferentes competencias, tanto de contenido (efecto Kouleshov, stop-motion, etcétera) como pedagógicas (trabajo colaborativo y Flipped Classroom, entre otros), pues se organiza mediante la metodología del aprendizaje por proyectos.
\end{abstract}

PALABRAS CLAVE: Estrategias didácticas, nuevas tecnologías, Séptimo Arte, aprendizaje por proyectos, trabajo colaborativo en el aula.

\section{"YOUTUBESCOPES": AN EXPERIENCE OF INNOVATION AND CREATIVITY FOR AUDIOVISUAL CULTURE THROUGH PROJECT-BASED LEARNING}

\footnotetext{
ABSTRACT: This article describes and analyzes the design called "Youtubescopios", an innovation, creativity project to complement the audiovisual content of different subjects in Secondary and High Schools. It consists basically in using the application of technologies added to smartphones in order to learn and recreate the features of the Seventh Art in its origins. It also aims to promote different skills, both content (Kouleshov effect, stop-motion and so on) and pedagogical (collaborative working and Flipped Classroom, among others), because it is organized by the methodology of project-based learning.
} 
KEYWORDS: Teaching strategies, new technologies, Seventh Art, projectbased learning, collaborative working in the classroom.

Recibido: 22/10/2016

Aceptado: 15/07/2017

Correspondencia: Angélica García-Manso, Universidad de Extremadura, Avda. de la Universidad, s/n., 10003 Cáceres. Email: angmanso@unex.es.

\section{INTRODUCCIÓN. El PROYECTO EN El MARCO ADMINISTRATIVO DEL SISTEMA DE Educación en la Comunidad Autónoma de Extremadura}

De acuerdo con la convocatoria de la Secretaría General de Educación de la Consejería de Educación y Cultura del Gobierno de Extremadura de 13 de agosto de 2014 (DOE de 2 de septiembre), en su segunda edición, se emplazaba a los centros escolares sostenidos con fondos públicos a participar en proyectos de innovación educativa para el curso académico 2014-2015. En la naturaleza de tales proyectos se primaba, entre otros aspectos de interés, "la aplicación didáctica y de gestión educativa de las tecnologías de la información y la comunicación, especialmente aquéllas que supongan una mejora efectiva del rendimiento académico del alumnado $^{\prime 1}$, y permitía la solicitud a título individual de un único profesor como responsable del proyecto, aunque éste en todo momento debía estar avalado por el centro educativo.

La autora del artículo que el lector tiene entre sus manos, en calidad de miembro del claustro de profesores del Centro Concertado "Colegio Sagrado Corazón de Jesús" de Cáceres en el momento de la citada convocatoria, con docencia en ESO y Bachillerato (además de ser tutora de uno de los cursos), y contando, además, con una formación curricular previa acorde con los objetivos, elaboró un Proyecto de Innovación y Creatividad educativa con el nombre simplificado de Youtubescopios con el fin de participar de acuerdo con las disposiciones establecidas por el Gobierno de Extremadura. El presente estudio aborda de forma académica y científica -es decir, dejando al margen las cuestiones de burocracia administrativa y las de carácter económico- las aportaciones didácticas del citado proyecto, sin menoscabo de la adecuación al currículo y de la viabilidad de los recursos, que, aunque aparecen como requisitos formales en la convocatoria, constituyen de por sí elementos indispensables para su planteamiento y desarrollo.

A este último respecto, si bien el objetivo último del proyecto que en su día presentamos incumbe a la asignatura de "Cultura Audiovisual", del Bachillerato de Artes (según se establece en la Ley Orgánica 8/2013 y mantiene el Real Decreto 1105/2014), al darse la circunstancia de que éste no se impartía en el centro se planteó con una triple intención complementaria: en primer lugar, como propuesta de intervención en el marco del curso tutelado y, en caso necesario, en sesiones

1. Diario Oficial de Extremadura, $\mathrm{n}^{\circ}$ 169, 2 de septiembre de 2014, p. 26645. 
complementarias o trasladables al ámbito de las actividades extraescolares; en segundo lugar, como complemento formativo de las asignaturas de Ciencias Sociales e Historia del Arte, de conformidad, por lo demás, con las competencias activas y pasivas sobre la representación audiovisual y su expresión que postula la legislación; y, finalmente, de cara al estudio de una hipotética implantación en el centro sea de un Bachillerato de Artes o de algún ciclo de Formación Profesional Básica relacionado con los medios audiovisuales e informáticos. El objetivo subyacente era la no discriminación de los alumnos interesados (entre doce y quince), si bien los participantes procedían en su mayor parte (un 80\% aproximadamente) del curso del que la responsable del proyecto era tutora y de asignaturas impartidas en su carga docente regular como profesora, a pesar de que la participación en el proyecto no era académicamente evaluable.

No se trata de un modelo didáctico, sino de una experiencia concreta; es decir, no se pretenden ofrecer unas pautas de intervención pedagógica o los resultados estadísticos de una encuesta al respecto, sino exponer un proceso cerrado, que se puede repetir como práctica para el aprendizaje de conceptos específicos acerca de los recursos del cine en sus inicios; de ahí que no se haga precisa la secuencia de metodología más resultados y discusión, según es habitual. A cambio se presenta la descripción de los trabajos llevados a cabo por los alumnos, los contenidos académicos logrados y las competencias adquiridas. De cualquier forma, según se podrá comprobar en los siguientes epígrafes, Youtubescopios se imbrica perfectamente en los requisitos de metodología activa y participativa, en calidad de aprendizaje colaborativo que exige la pedagogía actual, hasta el punto de que, en buena medida, se inscribe en los presupuestos del "Aprendizaje por Proyectos" (Johnson y Johnson, 1999; Trujillo, 2015). En efecto, de acuerdo con tales presupuestos, los conocimientos que se adquieren se supeditan a una orientación práctica, en concreto a la realización de pequeñas producciones audiovisuales en las que se haga patente la adquisición de conceptos y habilidades. Hacer frente a dicha realización implica un trabajo individual previo y un trabajo en equipo, sin el que no existirían resultados, según podrá apreciarse.

En otro orden de cosas, al respecto del trabajo individual, Youtubescopios es, en realidad, el marco de un trabajo del que se obtiene una percepción y un conocimiento a largo plazo -de tipo diacrónico y estético, pues, al fin y al cabo, son los alumnos los que reconstruyen las formas de entender el Séptimo Arte en sus orígenes- más allá de las películas realizadas. A este respecto, el proyecto responde igualmente al sistema de "Flipped Classroom", toda vez que los estudiantes implicados consultaban en Wikipedia y en los manuales de referencia ofrecidos por la profesora las características formales del cine mudo, siendo orientados únicamente en relación con la estética cinematográfica resultante. Así, el estudiante conocía aspectos como el dominio del plano general, la necesidad de escenografía teatral incluso para reproducir exteriores, la importancia de la expresión facial, la velocidad de reproducción, el recurso a intertítulos, etcétera, abordados en la consulta. De igual forma, podían acceder a producciones mudas en la red que les ofrecían modelos de actuación. En lo que se refiere a las experiencias concretas, si bien el profesor establecía los contenidos de -efecto Kouleshov-, etcétera, los alumnos documentaban su definición con anterioridad a las reuniones programadas. Se trata de requisitos aplicados en experiencias 
concretas de Flipped Classroom en tiempos recientes -según puede constatarse, por ejemplo, en el monográfico que dedica al sistema la revista Comunicación y Pedagogía (2015), 285-286-. Finalmente, es de destacar el carácter predominantemente participativo tanto en la distribución de papeles como en el hecho de que todos los alumnos pueden ocupar la coordinación del grupo, según decisión dejada en manos de los propios participantes, según se podrá comprobar. Todo ello sin necesidad de evaluación académica mediante calificaciones.

\section{TRASCENDENCIA DEL PROYECTO: INTERESES PEDAGÓGICOS Y DE CONTENIDO}

Mediante cualquier encuesta en el aula, por informal que sea el sondeo, se descubre que, en general, el estudiante de ESO y Bachillerato desconoce el cine antiguo y que apenas ha visto películas en blanco y negro y sin sonido. En ocasiones, ignora que haya existido tal cine -algo patente incluso en los niveles de educación superior, al hacerse necesarios ciclos como "Mudos de Asombro"2-, lo cual revela el interés didáctico intrínseco de Youtubescopios. Dos son sus orientaciones: una genérica (el aprendizaje a través de un proyecto) y otra concreta (el estudio de los orígenes del cine y su actualidad). Es el propio proyecto el que busca conferir a los alumnos los conocimientos que abordan la forma de entender el Séptimo Arte hace un siglo así como definir sus características, como paso previo a ponerlas en práctica en la realización de pequeñas películas.

Desde una perspectiva metodológica, no obstante, en la presentación del proyecto se ha de poner énfasis en el hecho de que el Ilamado cine mudo o silente no ha desaparecido (Establés y Manzur, 2014). Tres ejemplos pueden servir para constatarlo:

1. La existencia de filmes contemporáneos que recuperan las formas del cine mudo, tratándose, además, de películas que se han estrenado con normalidad en salas, han obtenido premios conocidos y son fáciles de conseguir, como The Artist (2011, de Michel Hazanavicius) y Blancanieves (2012, de Pablo Berger). Incluso hay un festival internacional dedicado a esta forma de cine como es el Toronto Silent Film Festival, con cine experimental y directores de relieve como el canadiense Guy Maddin, entre otros.

2. La presencia de recursos del cine mudo en la publicidad, los videoclips y los canales de Youtube (caso de Lumière Factory).

3. El cine mudo como recurso formal en series y películas de dibujos animados, con escenas construidas mediante teatro de sombras, decoloración en blanco y negro o sepia, movimiento ralentizado, etcétera. Así puede apreciarse, por señalar un único ejemplo, en el elaborado capítulo 45 de la segunda temporada de la serie de animación mediante técnicas CGI Peter Rabbit ${ }^{3}$, el titulado The Tale of the Unexpected Discovery, donde, a través del recurso del metraje encontrado o "found footage" se descubren citas a las primeras grabaciones cinematográficas de la Historia.

2. Celebrado durante los cursos académicos 2007/2008 y 2008/2009 en la Facultad de Filosofía y Letras de la Universidad de Extremadura, organizado por el Vicerrectorado de Extensión Universitaria bajo la dirección de Francisco Sánchez Lomba y Angélica Garcia-Manso.

3. Año 2012 y siguientes; USA, Ireland y United Kingdon; SilverGate Media y Brown Bag Films. 
Otro aspecto de interés sobre los conocimientos del cine en sus inicios se refiere a su carácter diegético, es decir, a si es ineludible el relato, la narración de acontecimientos. La Historia del Séptimo Arte refleja, por el contrario, que la intención originaria respondía a la plasmación de anécdotas aisladas y, a través de una figura como Georges Méliès, a los trucos y parafernalia propios de los espectáculos de magia; o, desde la reflexión soviética, a cómo tales anécdotas y trucajes se trasladan a las posibilidades expresivas de la imagen y su interpretación, contexto en el que se explica el conocido "Efecto Kouleshov", que también se buscó repetir en Youtubescopios. Ello resulta importante por cuanto se arma al estudiante para hacer frente a las trampas inherentes a la imagen y se hace con un sentido críticamente activo.

En fin, la propia Historia del Séptimo Arte se presenta a los estudiantes como una forma de aprender a leer la imagen en movimiento que define al cine en su evolución técnica (sobre el sonido, el color, la velocidad de la imagen o el montaje) y estética (con las aportaciones de David W. Griffith, los cineastas rusos y el expresionismo alemán, entre otros), hasta el punto de que incluso las características elementales con las que se reconoce académicamente el cine de los pioneros no permiten englobar el conjunto de producciones de los primeros años del Cine, ni su relación con las posibilidades de expresión actuales (aplicadas incluso a la educación física; Muñoz, 2013). De esta manera, se buscó hacer hincapié en distinguir el proceso químico frente al proceso digital, o, por poner un ejemplo diferente, el proceso de morphing rudimentario que supone la superposición de imágenes frente a la disolución visual que permiten las herramientas informáticas del presente. De alguna forma, se trata de mostrar también cómo en numerosas ocasiones el arte "hace de la necesidad virtud", conforme reza el aforismo tradicional, de tal forma que una velocidad "a saltos" permite efectos de relatividad física, es decir, permite explicar visualmente las teorías de Einstein, por destacar una figura clave de la ciencia actual.

Finalmente, el proyecto MuPAI (Museo Pedagógico de Arte Infantil), de la Universidad Complutense de Madrid, en lo que se refiere a la creatividad escolar mediante películas en cualquier formato ${ }^{4}$, no sólo funcionó como fuente de inspiración a la hora de plantear Youtubescopios, sino también como referente técnico a partir de la accesibilidad y facilidad de manejo de los recursos (Antúnez y Castro, 2010; Antúnez y Castro, 2015).

\section{ACCESIBILIDAD, PROXIMIDAd Y MANEJO DE LOS RECURSOS TÉCNICOS: SMARTPHONES Y APPS}

Youtubescopios plantea su desarrollo a lo largo del tercer trimestre del curso. Dado que su objetivo material era la realización de clips o pequeños cortometrajes, la planificación del trabajo estuvo orientada de forma práctica (Andreu y Martín, 2014): una vez establecidos en la sesión de presentación los rasgos singulares que definen el cine pionero -aspectos sobre los que los estudiantes implicados habrían de trabajar individualmente con carácter previo a la siguiente sesión-, se estableció una brainstorm (Iluvia o tormenta de ideas) al respecto de los posibles trabajos, de los que se seleccionaron cinco en virtud de su sencillez, viabilidad y originalidad, además

4. Según puede observarse en https://mupaidecine.wordpress.com/ [Obtenido 25 julio 2016]. 
de sugerir los nombres de los coordinadores en función de la coherencia con que expusieron las hipotéticas producciones, si bien primó la autoría grupal y anónima, bajo el epígrafe del nombre del proyecto.

Entre otras ideas se abordó la importancia de exagerar los gestos del rostro, el sentido de angular el enfoque en el plano (es decir, de inclinar la cámara), el trabajo al aire libre o en interior -con o sin escenografías y disfraces-, la posibilidad de romper una secuencia progresiva mediante saltos (con tres consecuencias: unos movimientos robotizados, la desaparición de objetos o la aceleración de acciones), el uso o no de soporte musical o alfabético mediante intertítulos, y la posibilidad de actuar con objetos a los que conferir movimiento de distintas formas (entre las que se contaba con el proceso de grabación imagen a imagen), etcétera, de acuerdo con un proceso de aprendizaje en torno a la imagen al que también se aplican los recursos pedagógicos de la Flipped Classroom (Ballarín y Cabezudo, 2015).

En lo que se refiere a la parte práctica, y según se podrá comprobar en los próximos párrafos, la facilidad de acceso a los medios técnicos permitía mucha flexibilidad para contar con la mayor parte de los alumnos participantes en las reuniones de rodaje, montaje y visionados de prueba (Checa et al., 2011), que se desarrollaron prioritariamente por las tardes (aunque algún rodaje se hizo por la mañana), a lo largo de una decena de sesiones. De éstas, tres fueron teóricas, cinco prácticas, una de presentación y otra, la última, de exposición y comentario de los trabajos realizados.

Por lo demás, el recurso tecnológico fundamental venía aportado por los propios estudiantes; se trata de sus teléfonos móviles inteligentes o smartphones (Boj y Díaz, 2014; para otro tipo de prácticas docentes, vid. Gómez y Castro, 2016). Los alumnos cuentan con un móvil personal que, si bien se aconseja que no sea utilizado en el colegio, lo cierto es que lo llevan habitualmente en sus bolsillos y mochilas. Los dos sistemas operativos de mayor difusión a fecha de hoy (iOS y Android) permiten su uso sin mayores requisitos técnicos, pues vienen instalados en los terminales (con predominio absoluto de Android en lo que se refiere a las propuestas creativas ofrecidas en Youtubescopios, y ello, probablemente, por motivos económicos). Cualquiera de los aparatos es susceptible tanto de grabar imágenes en vídeo como de albergar aplicaciones para la edición de películas (Alonso, 2015), además de otros programas y apps específicas para conferir un aspecto antiguo a las imágenes, a las que nos referiremos en un parágrafo posterior. A este mismo respecto, la calidad de la imagen pasa a un segundo plano, por cuanto, a la hora de emular el trabajo de los primeros cineastas, la baja nitidez puede contribuir a dotar de un aire más añejo a estas producciones amateur. El trabajo en interior es también posible con la mayoría de las lentes y sensores de los smartphones, si bien se propugnan realizaciones tanto con luz solar como artificial. Además, el entorno de los rodajes, exterior e interior, es el propio centro escolar con el fin de circunscribir temas y formas al mismo ámbito pedagógico del proyecto.

Así pues, el número de cámaras potenciales coincide con el número de alumnos participantes con sus respectivos teléfonos móviles, salvo en aquellos trabajos en los que éstos hagan de actores (en un número pequeño, ciertamente). De esta forma, el 
abanico de selección de raccords o imágenes y escenas de continuidad así como la necesidad del montaje son amplios y permiten experimentar simultáneamente distintas angulaciones y juegos de luces y sombras.

En principio, no es necesario el uso de las redes telefónicas, salvo para que los estudiantes se intercambien las grabaciones a través de mensajes vía Whatsapp o mediante conexión Bluetooth entre sus terminales, al igual que trasladar los trabajos al ordenador o para su "subida" final a un canal configurado en Youtube a nombre del colegio (Murolo, 2010; González, 2012), en el caso de que se autorice con los permisos paternos y administrativos pertinentes. De igual forma, se tenderá a trabajar en el propio terminal telefónico, salvo que sea necesario el volcado de las grabaciones en soporte ordenador, para los que existen programas como After Effects y Adobe Premiere (ambos de Adobe Systems, con sede en California), en cuyo manejo es posible iniciarse a través de tutoriales volcados en la plataforma Youtube.

En lo que se refiere a los smartphones, entre los recursos digitales no nativos o preinstalados en los móviles pueden mencionarse las aplicaciones necesarias para conferir un aspecto de primeros rudimentos de la Historia del Cine a los trabajos; se trata principalmente del volcado a tonos grises y sepias, la ausencia de sonido intradiegético, el rayado y quemado de la imagen y, algo importante también desde la perspectiva de los contenidos, el recurso a intertítulos. También se puede optar por configurar programas de edición para lograr tales efectos, pero éstos son de carácter profesional y, por ello, de mayor complejidad y ralentización a la hora de visualizar los resultados en el propio teléfono. No obstante, existen pequeños programas que simplifican dichas labores en aplicaciones reducidas y más enfocadas a la idea de realización de un filme mudo. Tales aplicaciones son de libre circulación o su precio es perfectamente asumible (en torno a un euro). El mercado a este respecto es muy dinámico y tanto los programas como los responsables, en muchas ocasiones aficionados a la programación de los sistemas operativos para smartphones, varían de continuo. Los motores de búsqueda de los programas facilitan, no obstante, tanto la localización de nuevas versiones como la actualización de apps previas. Poco importa, en fin, que en ocasiones se den unos límites de tiempo de grabación reducidos (de hasta un minuto), por cuanto la concentración constituye también una de las características del cine pionero.

Ofrecemos dos sencillos ejemplos para el sistema android: la app Old Movie Camera (propiedad de la empresa argentina Msistemas Studio, y de libre distribución) permite grabar directamente con la apariencia de cine mudo además de volcar a monocolor, oscurecer y rayar una secuencia preexistente, como recursos básicos para el proceso de conversión. Por su parte, la app Kamarada (de la empresa Videona Socialmedia, con sede en España, cuya instalación en los sistemas tiene un precio de 0.79 euros) ofrece más variedad de efectos y filtros de cine mudo, sin límite de almacenaje en lo que se refiere a la duración de los vídeos. La clave estética radica en el contraste y la compensación de la luz, que refuerza el aspecto arcaizante de los resultados, además de las posibilidades que ofrece para regular la velocidad de las tomas o su volcado posterior, dado que la ralentización constituye una de las características más evidentes del cine mudo.

Otro aspecto de enorme interés, a pesar de que normalmente no se incide en éste en los planes de estudio de Secundaria y Bachillerato, se refiere al análisis, reconoci- 
miento y uso de tipografías, sobre todo en lo que se refería a los títulos de crédito y los intertítulos. En la actualidad existen modelos que se inspiran en los alfabetos déco que están presentes en buena parte del cine antiguo, dado que coincidieron técnica y movimiento artístico, aspecto importante también como forma de aprendizaje para los alumnos. Por poner ejemplos contemporáneos de fuentes elaboradas digitalmente e inspiradas en letras déco y del cine mudo -conocidas como "tipografías vintage"-, se pueden considerar entre las de libre distribución: Bellerose, Little Lord Fontleroy, Fontleroy Brown, Broadway Regular, Chentelham Condensed Bold, Nickelodeon, SpeedBall o Albertus ${ }^{5}$.

El trabajo de documentación, en fin, implica el conocimiento y acceso a webs específicas sobre cineastas pioneros, como, por citar únicamente una, la de George Méliès ${ }^{6}$.

\section{CinCo PROPUESTAS GeNeRADAS EN EL MARCO DE LOS ObJetivos Del PROYeCtO YOUTUBESCOPIOS}

Según se ha descrito, Youtubescopios es, ante todo, un proyecto de carácter escolar, colaborativo y no evaluable mediante calificaciones académicas, conforme a las pautas que establece, entre otros, Sánchez Rincón (2011) a la hora de definir sus objetivos y las competencias que se esperan, aunque sin entrar en discusión de detalles metodológicos. $Y$ es que se trata de una propuesta muy concreta en torno a los orígenes del Séptimo Arte, y basada fundamentalmente en la descripción de su puesta en práctica. La distribución de objetivos específicos partió de cinco líneas de trabajo que destacan la singularidad estética de los orígenes del cine:

- El análisis del Efecto Kuleshov (o sobre la subjetividad de la interpretación de una imagen en función de su contexto o prejuicio).

- La velocidad de la imagen (tanto en calidad de percepción relativa como de relatividad física).

- El trucaje mediante la elisión de fotogramas (conforme a recursos de prestidigitación y magia).

- La "stop-motion" (sistema de animación fotograma a fotograma).

- La "selfie" especular (como paradigma cultural de la tecnología contemporánea y su ensimismamiento).

De igual forma, en determinados casos se recurrió a acompañar las imágenes con intertítulos que no sólo ilustraban la imagen sino que, en ocasiones, la comentaban de forma irónica.

A continuación se describen los trabajos efectuados y las competencias obtenidas:

\section{Emoticones}

Emoticones fue el título elegido para plasmar el "efecto Kuleshov". Se trataba de acercar a los compañeros al tablón del aula en el que se acababan de clavar las califi-

5. Vid. www.dafont.com/es/ [Obtenido 25 julio 2016].

6. http://www.melies.eu/ [Obtenido 25 julio 2016]. 
caciones de una asignatura e ir alternando, mediante montaje, el rostro de una alumna ante las diferentes calificaciones, el cual evolucionaba desde la incredulidad hasta la satisfacción contenida, a pesar de que se daban dos opciones, el mismo rostro o las reacciones de rostros diferentes pero en situaciones distintas: rostro de estupefacción ante una mala nota y rostro de sorpresa ante una buena nota, invertidos. Mediante los intertítulos se informaba sobre la calificación, remarcando enfáticamente el tablón del aula que se mostraba en la imagen.

La competencia doctrinal que se promovía se refería no tanto al montaje formal cuanto a la manipulación psicológica, de índole subliminal, que establece la lectura que el espectador hace del rostro que aparecía en pantalla. El título Emoticones resulta, al cabo, elaborado y sugerente al respecto de cómo el efecto Kuleshov fomenta equívocos en las redes sociales a la hora de utilizar los símbolos gestuales acompañando a determinadas informaciones o referencias. La duración de la propuesta era de un minuto.

\section{La gran carrera}

La gran carrera recoge una única competición de atletismo -una carrera de 50 metros- en la que, sin embargo, se combinan mediante montaje dos carreras. En la primera interviene como protagonista un actor caracterizado con un aparatoso disfraz de caracol, en tanto que en la segunda, con el mismo fondo y disposición de los tres competidores restantes, no corría en realidad el personaje. Ahora bien, en el montaje, éste avanzaba dando enormes zancadas hasta vencer, apareciendo y reapareciendo en pantalla como mediante guiños.

Los alumnos aprenden no sólo la paradoja de Zenón de Elea sobre Aquiles y la tortuga, sino también el uso de varias cámaras y la manipulación sobre las velocidades, siendo la ralentización, precisamente, uno de los rasgos del cine mudo que más contradicción establece con la aceleración de blockbusters contemporáneos, según se descubre en un filme como Furia de Titanes en sus dos versiones, la original de Desmond Davies (1981) y su remake, fuertemente acelerado, a cargo de Louis Leterrier (2010). La ironía final sobre la liebre y la tortuga o Aquiles y la tortuga se establecía mediante intertítulos. La duración del cortometraje era de menos de un minuto. Desde una perspectiva técnica se pretendían parodiar también recursos contemporáneos como el time-lapse o concentración de los intervalos de sucesos de rodaje para aglutinarlos en un tiempo más reducido (Sánchez y San Julián, 2014); o, en otras palabras, la aceleración de procesos lentos, como el paso de las nubes o un capullo que se abre.

\section{Catástrofe en el aula}

Catástrofe en el aula consiste en la reconstrucción de un breve trabajo inspirado directamente en el pionero Georges Méliès en su faceta como mago, que hace desaparecer objetos y personas de pantalla. La propuesta se abre con un encuadre desde el fondo de un aula en la que se observa a unos cuantos estudiantes aburridos, con la cabeza recostada sobre sus pupitres, quienes despiertan ante la brusquedad con la que se pone en pie la profesora sobre la tarima de su mesa. Acto seguido, ésta 
avanza violentamente hacia la parte delantera del escritorio, pero de pronto desaparece, para algarabía de los alumnos arrojando sus lápices al aire tras haber provocado una nube de humo con el polvo de tizas antiguas.

Al margen de la broma, y de la confusión entre realidad y sueño, o entre verdad y deseo, el sketch (de apenas medio minuto de duración) permite mezclar la teatralidad inherente al cine en sus inicios con un doble efecto sorpresa: la brusquedad del gesto de la profesora en medio de la monotonía de la clase y su desaparición en una nube de polvo de tiza sobre la que se superpone otra nube de lápices lanzados al aire, cuya caída se evita al detenerse la imagen final, en una especie de clausura in medias res o "continuará", conforme se puede ver en infinidad de producciones cinematográficas y televisivas.

\section{El libro que se estudia solo}

El libro que se estudia solo consiste en un trabajo en stop-motion (García, 2012; Herráiz, 2014), centrado en los movimientos autónomos de un libro sobre un pupitre, su disposición en horizontal y vertical, de pie y tumbado, el paso de las páginas, cómo éstas se pliegan de forma papirofléxica, y culmina con el libro arrojándose desde la mesa, en un aparente suicidio, pero que se abre en páginas con una sonrisa a la manera de un "emoticón". Y es que mediante la stop-motion lo estático cobra movimiento (incluso desde perspectivas interdisciplinares y relacionadas con la Didáctica de las Ciencias Sociales, según Vidal y Ventura -2014-).

Se trata de una propuesta donde la clave radica en la ausencia de seres humanos $y$, al tiempo, en el proceso de humanización de un objeto tan propio de la especie como es un libro, proceso que culmina con una esquemática sonrisa. La ausencia de personajes y la animización de objetos constituyen también un recurso propio del cine pionero y de la trascendencia que en éste tiene la prosopopeya como una de las capacidades técnicas del medio, capaz de hacer antropomorfos a los animales y de dar vida a las cosas. Cuarenta segundos de falso movimiento coparon el tiempo de la propuesta.

\section{Una "selfie" antigua}

En realidad, una selfie no puede fotografiarse, al igual que una cámara no puede fotografiarse a sí misma sin el concurso de otra cámara, salvo que se haga ante un espejo. ¿Hasta qué punto se están haciendo pasar por selfies o "autofotos" fotografías de proximidad? Desde la perspectiva del proyecto Youtubescopios, la conversión de un smartphone en cámara para ser fotografiado como tal, precisaba convertir previamente el teléfono móvil en una cámara antigua, voluminosa, con aspecto de caja y con trípode, para fotografiarla desde otro smartphone al tiempo que el móvil incrustado hacía una foto de grupo mediante el bastón específico para selfies o, en otra ocasión, se hacía una foto a sí misma frente a un espejo. La suma de teléfono móvil camuflado de cámara de cine de los pioneros fotografiándose a sí misma mediante un bastón al tiempo que todo el proceso es fotografiado y grabado constituía el objetivo de la propuesta.

Se trata de un trabajo sutilmente irónico (a la manera de la película The Cameraman-1928-, de Buster Keaton), con el que se pretendía enfrentar la cámara antigua con el móvil actual, documentar su metamorfosis (con el palo para selfies como trí- 
pode), ofrecer una trama en torno al tema del "cazador cazado", y, finalmente, sugerir la autocrítica de emplear tecnologías potentes para recrear sistemas obsoletos que, en realidad, no se podrían utilizar hoy en día, pues ni hay películas ni conocimientos para su revelado, por ejemplo. Todo ello en medio minuto. Por lo demás, la capacidad de generar autocrítica encarna la competencia clave de esta propuesta concreta.

\section{CONClUSIÓN: LA CRÍtICA DE LA IMAGEN COMO COMPETENCIA EDUCATIVA}

Tanto desde la perspectiva del aprendizaje colaborativo y el sistema de Flipped Classroom como desde la específicamente relativa al aprendizaje a través de proyectos, Youtubescopios se ofrece como un proyecto centrado en los inicios de la imagen en movimiento y en su tratamiento mediante artilugios contemporáneos como los smartphones (Ramírez, 2010). El alumno investiga, de un lado, las características del Séptimo Arte en sus orígenes y, de otro lado, lleva a cabo una propuesta concreta en la que se reflejen dichas características utilizando aplicaciones digitales contemporáneas. Conocimientos y creatividad se aúnan como logros competenciales que no descartan algo clave: la adopción de posturas críticas ante las manifestaciones audiovisuales del presente, sean de índole ideológica o meramente mercadotécnica.

Como logro añadido, el estudiante hace frente a la Historia del Cine para entender filmes mudos y en blanco y negro a los que normalmente no presta interés a pesar de sus valores intrínsecos. Igualmente, el proyecto permite mostrar el peso de la contaminación acústica del presente al optarse por eliminar la banda sonora intradiegética o, de forma más radical, presentar trabajos sin sonido. La necesidad de establecer guiones con una enorme concentración narrativa revela una importante capacidad de síntesis para discriminar lo fundamental de lo accesorio. Los intertítulos, en fin, se descubren como una parodia de los smss y whatsapps actuales, cuya mera formulación reflejaban la rica y sutil ironía y creatividad de los estudiantes.

En verdad, los resultados no tienen por qué ser espectaculares en el plano formal -poco profesionales, en verdad, como era de esperar-, pero es perfectamente posible la consecución de los objetivos propuestos. El nombre del proyecto, por lo demás, quería evocar las formas del "precine" fusionadas con las redes digitales contemporáneas, con evocación del "praxinoscopio" o del "kinetoscopio", entre otros. De esta forma, a partir del nombre del canal de difusión de películas de mayor divulgación en Internet, con el añadido del verbo griego referido a la mirada, surgiría un término como "canal-tú-mirada", que posee sentido individual y colectivo, divulgativo y crítico, actual y antiguo, entre otras connotaciones.

\section{REFERENCIAS BIBLIOGRÁFICAS}

Alonso Valdivieso, C. (2015). Enseñar con Motion Graphics. Relatec. Revista Latinoamericana de Tecnología Educativa, 14. http://doi.org/10.17398/1695-288X.14.3.75.

Andreu Sánchez, C. y Martín Pascual, M. A. (2014). La narrativa transmedia audiovisual a través de plataformas móviles: creación de transmedia, una aplicación real en un entorno educomunicativo. En J. Sierra Sánchez y F. García García (Eds.), Tecnología y narrativa audiovisual (pp. 153-168). Madrid: Fragua. 
Antúnez del Cerro, N. y Castro, J. A. (2010). MuPAI animado: propuestas educativas para adolescentes sobre técnicas de animación en la creación audiovisual. Arte, individuo y sociedad, 22, 91-102.

Antúnez del Cerro, N. y Castro, J. A. (2015). Del set a la red. Introducción a la Filmografía del MuPAI (2007-2014). En M. San Andrés Mova (Ed.), Congreso Internacional Museos Universitarios. Tradición y Futuro (pp. 431-437). Madrid: Universidad Complutense.

Ballarín Romero, L. y Cabezudo i Fors, I. (2015). La metodología Flipped Classroom en la enseñanza de la fotografía. Comunicación y Pedagogía: Nuevas tecnologías y recursos didácticos, 285-286, 89-94.

Boj Tovar, C. y Díaz, D. (2014). Narrativas espaciales y telefonía móvil: herramientas para el análisis de un nuevo formato audiovisual. En J. Sierra Sánchez y F. García García (Eds.), Tecnología y narrativa audiovisual (pp. 891-900). Madrid: Fragua.

Checa Romera, M., García Varela, A. B., del Castillo Fernández, H., Monjelat, N. y Casas, X. (2011). Cultura participativa y machinima: creaciones audiovisuales en las aulas. En M. Gértrudix Barrio, F. Gértrudix Barrio y F. García García (Eds.), Actas II Congreso Internacional Sociedad Digital: Espacios para la interactividad y la inmersión (pp. 227-241). Madrid: Asociación científica Icono 14.

Establés Heras, M. J. y Manzur Herrá, K. (2014). Cine mudo y videoclips musicales: una propuesta para enseñar narrativa audiovisual en las aulas. En J. Sierra Sánchez y F. García García (Eds.), Tecnología y narrativa audiovisual (pp. 245-262). Madrid: Fragua.

García Martínez, J. D. (2012). Stop-motion: comunicación, creación y diversión. Caracteres: estudios culturales y críticos de la esfera digital, 1, 107-118.

Gómez García, I., Castro Lemus, N. y Toledo Morales, P. (2016). La Flipped Classroom a través del Smartphone: Efectos de su experimentación en educación física secundaria. Prisma Socia. Revista de Investigación Social, 15, 296-351.

González Álvarez, F. J. (2012). Utilización de Youtube como recurso didáctico. En M. Raposo Rivas y M. E. Martínez Figueira (Eds.), As TIC e as súas aplicacións na aula: misión posible (pp. 59-70). A Coruña: Toxosoutos.

Herráiz Zornoza, B. (2014). Stop Motion Don`t Stop, la exposición. Con A de animación, 4, 56-64. http://doi.org/10.4995/caa.2014.2161.

Johnson, R. G., Johnson, D. W. y Holubec, E. J. (1999). El aprendizaje cooperativo en el aula. Barcelona: Paidós.

Muñoz Álvarez, T. (2013). Propuesta didáctica: Los protagonista de Cine Mudo. EmásF: revista digital de educación física, 24, 44-55.

Murolo, R. L. (2010). Post-zapping: transmite tú mismo: Youtube como la televisión posmoderna. Razón y palabra, 71. Recuperado de http://www.razonypalabra.org. mx/N/N71/VARIA/14\%20MUROLO-REVISADO.pdf.

Ramírez García, A. (2010). Youtube y el desarrollo de competencias básicas: una experiencia de investigación en el aula. En J. M. Pérez Tornero (Ed.), Alfabetización mediática y culturas digitales. Barcelona: Gabinete Comunicación y Educación (UAB). Recuperado de http://www.gabinetecomunicacionyeducacion.com/sites/ default/files/field/adjuntos/youtube_y_el_desarrollo_de_competencias_basicas_ una_experiencia_de_investigacion_en_el_aula.pdf. 
Sánchez Fariñas, G. y San Julián Alonso, R. (2014). Del stop-motion al time-lapse: de atracción de feria a espectáculo del tiempo. En J. Sierra Sánchez y F. García García (Eds.), Tecnología y narrativa audiovisual (pp. 443-470). Madrid: Fragua.

Sánchez Rincón, F. E. (2011). El aprendizaje basado en proyectos como técnica didáctica en la pedagogía del cine: aplicación de una técnica didáctica. Comunicación, 28, 73-80.

Trujillo, F. (2015). Aprendizaje basado en proyectos. Infantil, Primaria y Secundaria. Madrid: Ministerio de Educación, Cultura y Deporte.

Vidal Prades, E. D. y Ventura Chalmeta, E. (2014). La interdisciplinariedad del stopmotion en Ciencias Sociales. En J. Pagès i Blanch y A. Santisteban (Eds.), Una mirada al pasado y un proyecto de futuro: investigación e innovación en Didáctica de las Ciencias Sociales (pp. 535-544). Barcelona: Universitat de Barcelona y Asociación Universitaria de Profesores de Didáctica de las Ciencias Sociales. 